\title{
Utopia como método: a reconstituição imaginária da sociedade
}

LEVITAS, Ruth. Utopia as method: the imaginary reconstitution of society. New York: Palgrave MacMillan, 2013.

Marcelo Augusto de Almeida Teixeira*

A busca da utopia está no cerne da sociologia e, mais do que nunca, é necessária uma reconciliação entre sociólogos e utopistas. É a partir desta premissa que a socióloga Ruth Levitas, professora da Universidade de Bristol, Inglaterra, desenvolve seu livro Utopia as method: the imaginary reconstitution of society, no qual sugere que a sociologia carrega em si inevitáveis elementos utópicos desde seu surgimento como disciplina. Utopia as method é uma continuação do anterior The concept of utopia ${ }^{1}$, no qual defende um conceito mais positivado, flexível e otimista para "utopia", tendo como fundamentação teórica a obra de Ernst Bloch, 0 princípio esperança, traduzido para o inglês em 1986. Para Levitas, a crise econômica de 2008, a atual recessão econômica da Europa, a falência em se atingir as Metas do Milênio da ONU, aliadas à crise ecológica que já ameaçaria a sobrevivência humana enquanto espécie torna emergente não só um revisionismo do conceito de utopia em quadros mais benéficos, mas também reconhecer as características utópicas da sociologia. Para a autora, utopia é o desejo de se viver ou de ser melhor e isto é inerente à condição humana. Eis aqui outra premissa importante na obra de Levitas: enxergar a utopia como desejo, enquanto prática, de uma sociedade melhor. Entretanto, Levitas reconhece que sociólogos tendem a abordar negativamente o conceito de utopia, equalizando-o com projetos totalitários: é o que chama de "discurso antiutópico", que permite a ascensão da subordinação aos ditados dos mercados capitalistas.

Considerar o conceito de utopia em termos de desejo é - para Levitas - proveitoso: sugere que assim se configura um método hermenêutico que com frequência nos leva de volta às preocupações estéticas e aos domínios sociais. Desta forma, Levitas explora a música, a arquitetura, a literatura e a sociologia como sítios de relações sociais idealizadas e práticas prefigurativas e transformativas de um mundo melhor: utopia, assim, passa a ser não apenas a idealização, mas o fazer de um mundo de outra maneira. A autora sustenta que a ideia de práticas prefigurativas de um mundo melhor já é a realização da utopia e que pode ser estendida para as relações sociais que se pretendem ou estão inseridas em tentativas de reformulação de uma
Recebido: 25.08.14

Aprovado: 04.03.15
* Doutorando PPG-SOL UnB.

1. Primeira edição de 1990, reeditado em 2010. 
sociedade melhorada. Assim, chama a atenção para as práticas utópicas cotidianas, nas quais práticas sociais alternativas ou oposicionistas ao atual status quo são capazes de moldar novas instituições sociais: aqui, a autora inclui comunidades alternativas como exemplo. Para Levitas, diversas práticas sociais e programas políticos (incluindo os da extrema direita) estão inseridos em ideais de uma "boa sociedade" e de tentativas para realizá-la.

Em seguida, sugere pensar em utopia de maneira mais holística, para além das práticas cotidianas e em direção a maiores estruturas sistêmicas e institucionais. Desta forma, a autora considera que esta maneira se amolda melhor ao pensar sociológico, não como uma sociologia especulativa, mas como reconhecimento das intrínsecas relações entre sociologia e utopia, já que as fronteiras entre utopianismo e prescrições sociológicas seriam porosas. Para Levitas, a reconstituição imaginária da sociedade (RIS) requer pensar nas conexões entre processos sociais, econômicos e políticos, em nossas maneiras de vida e no que seria ideal para a emancipação humana. Assim, reconhecer que existem interfaces entre utopia e sociologia implica repensar pressupostos sobre a própria sociologia: confronta a ideia de que a sociologia é uma forma de conhecimento enquanto a utopia é apenas especulação. Levitas, desta forma, sugere reconhecer o utopianismo não como especulações, mas como uma legítima, reprimida e existente forma de conhecimento de futuros possíveis.

Na segunda parte, Ruth Levitas analisa as imbricações entre sociologia e utopia, as críticas às utopias, seu revisionismo e um "retorno do reprimido", ou seja, da utopia no pensar sociológico. Para a autora, se a utopia é a expressão do que se sente falta, das lacunas de qualquer sociedade ou cultura, então um entendimento apropriado destas culturas ou sociedades deve levar em consideração suas lacunas e aspirações não preenchidas, suas visões de melhoramentos, suas especulações. De fato, a literatura utópica, por uma perspectiva histórica, demonstra as aspirações das sociedades que as produziam. Assim, Levitas sugere que devemos não só considerar as suposições utópicas sobre o que se deveria ser, mas também considerar a sociologia como utopia e esta como sociologia. Para fundamentar esta relação, a autora inicia um diálogo com Auguste Comte e, em seguida, apresenta os elementos utópicos que considera contidos na obra de Émile Durkheim e Charlotte Perkins Gilman, além de analisar autores que julga transitarem entre a sociologia e a utopia, como William Morris, Edward Bellamy e H. G. Well. Desta forma, Levitas pretende demonstra que haviam fortes comonalidades entre as preocupações da sociologia e a as prescrições da literatura utópica, especialmente no final do século XIX. Citando a autora, em tradução livre: 
enquanto elas mesmas fazem parte disto. Mas o fazem de maneiras levemente diferentes. A sociologia torna importante o que a utopia tem em segundo plano enquanto a utopia valoriza o que a sociologia reprime. Os modelos sociológicos são explicitamente holísticos, descritivos, explanatórios ou orientados para o presente ou o passado. São, necessariamente, imaginários: qualquer modelo de como a sociedade funciona implica uma reconstituição imaginária da sociedade. Modelos sociológicos são, às vezes, explicitamente críticos, normativos e prescritivos, mas, implicitamente, nossos exatos silêncios moldam utopias. Modelos utópicos são explicitamente holísticos, imaginários, críticos, normativos, prescritivos e - muitas vezes - orientados para o futuro. Apesar disso, a maioria destes contém descrições de condições presentes, não apenas como vias para melhores utopias, mas também como explicação de como processos sociais funcionam e que, portanto, precisam mudar. Neste sentido, são orientados para o presente. Mas utopia envolve a reconstituição imaginária da sociedade em um sentido levemente diferente: é o imaginar de uma sociedade reconstituída, sociedade imaginada de outra maneira, mais do que meramente sociedade imaginada (p. 83-84).

Na terceira e última parte do livro, Levitas esmiúça sua proposta de método para a RIS, a partir de três aspectos específicos: arqueológico, ontológico e arquitetônico. No primeiro aspecto - o arqueológico -, propõe colecionar e entender em conjunto imagens de sociedades melhoradas e/ou idealizadas contidas em programas políticos e políticas sociais e econômicas, apontando para as lacunas e inconsistências destas imagens: uma proposta de escavar e reconstruir os ideários políticos, econômicos e sociais, os quais, para a autora, sempre trazem à tona prescrições utópicas e de condições humanas melhoradas. Já no ontológico, sugere que nos preocupemos com os sujeitos e agentes envolvidos, interpelados, encorajados e permitidos pelo pensar utópico. Para Levitas, o aspecto ontológico da RIS é importante por dois motivos: primeiro, qualquer discussão de uma sociedade melhorada implica pensar em maneiras de ser consideradas superiores às atuais; segundo, a necessidade das utopias não só representam, mas também se voltam à esfera dos afetos humanos. Assim, a premissa que fundamenta o aspecto ontológico envolve reivindicações sobre quem somos, deveríamos ou poderíamos ser. Por fim, o aspecto arquitetônico não só nos leva a pensar sobre a delineação institucional e social de uma sociedade melhorada, mas também sobre sua materialização concreta e seus arranjos espaciais. No aspecto arquitetônico, a autora analisa delineações gerais como dignidade e igualdade humanas, renda básica, bom trabalho, cuidado e vulnerabilidade humanas, sustentabilidade. Em seguida, analisa propriamente o arquitetônico, já que não só muitas vezes as prescrições utópicas carregam arquiteturas idealizadas, mas também porque devemos pensar materialmente no que queremos ver construído em nossas sociedades imaginadas: escolas, creches, parques etc. Assim, Levitas sugere que a arquitetura 
torna-se importante na RIS, por ser o espaço fundamental para o bem-estar social e material: a arquitetura apropriada para a RIS é aquela que facilita interações sociais, menos predeterminadas por planejadores, arquitetos e pelo capital, sendo flexível para que os humanos criem coletivamente seus futuros dentro de seus espaços. Entretanto, Levitas alerta sobre a importância de não se pensar nestes três aspectos como diferentes métodos separáveis de RIS, e sim como um único e abrangente recurso, no qual ênfases podem ser variáveis. Assim, para se pensar em uma RIS, Levitas sugere serem indissociáveis os aspectos discursivos, espaciais, institucionais, coletivos e subjetivos (na esfera do sujeito) do processo. Finaliza seu livro com Marx, Bloch e Morris, ao considerar que devemos construir e construir a nós mesmos com dor, esperança, amor, imaginação e organização.

A obra de Ruth Levitas é fundamental para os estudos utópicos e sua valorização dentro da sociologia, inserindo-se em uma linha de pensamento que vê a utopia de forma positiva e que se afasta daquelas que veem o utopianismo como sinônimo de opressão, totalitarismo e violência. Por exemplo, Russel Jacoby (2005) alerta para a necessidade de distinção entre as utopias "diagramáticas" e as "iconoclastas", colocando-se a favor das iconoclastas, que seriam aquelas cujos atores recusam-se a desenhar imagens precisas e contornos definidos do mundo desejado, restando assim apenas a prática do que se deseja. Jacoby rejeita as utopias diagramáticas por suas tendências totalitárias, exemplificadas com a obsessão (expressa em muitos textos utópicos clássicos) de detalhar os mínimos detalhes da vida humana nas sociedades imaginadas. Para esse autor, os utopistas iconoclastas não fornecem imagens definidas por que o próprio ato de definição é constantemente refeito no momento presente, sendo a utopia, assim, um processo infindo: seria uma "atitude indecisa" entre duas zonas de tempo - a que habitamos agora e a que poderia existir no futuro (Jacoby, 2005: 146). Outros autores reforçam o conceito de utopia como prática, mudança da sociedade aqui e agora, guiados pelo desejo, como o fazem os teóricos "queers" Angela Jones (2013), José Esteban Muñoz (2009) e Elizabeth Grosz (2001): há em comum nestes autores a utopia como constante desempenho de maneiras prazerosas de "estar no mundo", uma corporificação de uma sociedade melhorada, de um mundo sexual, social e politicamente mais justo. Entre Ruth Levitas e estes autores há uma convergência explícita: se Levitas defende - no seu proposto aspecto ontológico da RIS - uma análise dos sujeitos envolvidos no pensar utópico, a utopia proposta pela teoria queer corporifica no corpo destes sujeitos a utopia. Desta forma, a própria existência destes sujeitos é um exercício utópico. A leitura de Utopia as method é instigante para se pensar sociologicamente sobre sujeitos, corpos, instituições e espaços físicos de nossas utopias e também para se pensar utopicamente sobre nossas práticas sociais, nossas instituições e mesmo em nossos corpos. Como disse Foucault (1966), "o corpo humano é o ator principal de todas as utopias". 


\section{Referências}

FOUCAULT, Michel. El cuerpo utópico, 1966. Disponível em: <http://www.pagina12. com.ar/diario/psicologia/9-155867-2010-10-29.html>. Acessado em: Ago. 2014.

GROSZ, Elizabeth. Architecture from the outside. Cambridge (MA): Massachusetts Institute of Technology (MIT), 2001.

JACOBY, Russell. Picture imperfect: utopian thought for an anti-utopian age. New York: Columbia University Press, 2005.

JONES, Angela (Ed.). A critical inquiry into queer utopias. New York: Palgrave Macmillan, 2013.

LEVITAS, Ruth. The concept of utopia. Peter Lang, 2010 [1990].

MUÑOZ, José Esteban. Cruising utopia: the then and there of queer futurity. New York: New York University Press, 2009. 